\title{
Microestrutura e propriedades de porcelanas
}

\section{(Porcelain microstructure and technical properties)}

\author{
S. R. Bragança, C. P. Bergmann \\ Laboratório de Cerâmicos - LACER \\ Universidade Federal do Rio Grande do Sul - UFRGS \\ Av. Osvaldo Aranha, 99/705, Porto Alegre, RS 90035-190 \\ saulorb@ufrgs.br
}

\begin{abstract}
Resumo
A microestrutura de uma porcelana tradicional, queimada a diferentes temperaturas, foi analisada e relacionada com suas propriedades técnicas. Investigou-se por ceramografia a morfologia de fases, determinando-se a presença de quartzo, mulita primária e mulita secundária. Este estudo foi apoiado por análise de microssonda EDX e difratometria de raios X. As propriedades dos corpos-deprova sinterizados mostram-se fortemente influenciadas pela fase vítrea e pelas fases cristalinas presentes, estas últimas preponderantes na definição da resistência mecânica final e tenacidade das peças.

Palavras-chave: cerâmica, porcelana, microestrutura.
\end{abstract}

Abstract

The microstructure of traditional porcelain sintered at different temperatures was analyzed and related to technical parameters. The morphology of the phases was investigated. Quartz, primary mullite and secondary mullite were found. The results were supported with experimental data using EDX and X-ray diffraction analysis. The properties of the sintered samples show to be strongly affected by vitreous phases, and this determine the quality of the ceramic pieces. The best sintering temperature was also a consequence of vitreous phase properties, like porosity. The crystalline phases were found responsible for the achieved strength . Keywords: ceramic, porcelain, microstructure.

\section{INTRODUÇÃO}

O termo microestrutura é utilizado para descrever as características estruturais encontradas nos materiais poligranulares (policristalinos ou polifásicos). As microestruturas podem ser caracterizadas pelo tipo, proporção e composição das fases presentes, e pela forma, tamanho, distribuição e orientação dos grãos.

No estudo dos materiais cerâmicos, a análise da microestrutura é empregada para explicar diferentes propriedades e, conseqüentemente, diferentes aplicações para os materiais. Uma amostra de um material de mesma composição química pode apresentar uma resistência à fratura bem superior à outra, mesmo que ambas tenham se submetido aparentemente ao mesmo processamento. Este fato bastante comum na análise dos materiais, quase sempre encontra explicação ao estudar-se a microestrutura, observando-se, por exemplo, o tamanho de grão, quantidade de fase vítrea, forma do poro, características essas acessíveis a técnicas de análise bastante simples.

O microscópio eletrônico de varredura (MEV) é uma ferramenta poderosa devido à alta capacidade de resolução de imagens, permitindo-se observar imagens com excelente nitidez com, por exemplo, 10.000 vezes de ampliação, ou seja, partículas de aproximadamente $1 \mu \mathrm{m}$ de tamanho (potencialmente, este equipamento apresenta ainda maior capacidade de resolução). A utilização do MEV auxiliado por microssonda EDX (Energy Dispersive X-ray) que permite a análise química elementar puntual, apresenta um recurso de grande valia na investigação da microestrutura. É preciso é claro se conscientizar das limitações e imprecisões desta análise, principalmente em um produto de porcelana, cuja fase vítrea permite relativa mobilidade a certos elementos, como o sódio, de modo que a composição química elementar pode apresentar significativa variação de um ponto a outro. $\mathrm{O}$ conhecimento da morfologia das fases e o auxílio do difratômetro de raios $\mathrm{X}$, na determinação das fases presentes, aumentam bastante a confiabilidade de uma análise, auxiliada também pela pesquisa bibliográfica.

O modo de preparação das amostras determina as características que se poderá observar na análise microestrutural. A fase vítrea superficial pode ser removida por meio de ataque ácido da amostra, durante a preparação da mesma para a análise por microscopia, revelando-se as fases cristalinas. Sem ataque ácido, observa-se principalmente a fase vítrea, algum contorno de fase e, possivelmente, a presença de bolhas de gás e trincas na fase vítrea. Assim, os resultados deste trabalho são apresentados considerando-se o método de preparação na investigação da microestrutura de uma porcelana.

Este trabalho objetiva, portanto, mostrar características que se pode observar na microestrutura de porcelanas que explicam as propriedades das mesmas. Assim, a perfeita correlação do processo de queima com as características da fase vítrea são 
mostradas. Esses aspectos ampliam-se para escolha e seleção de fundentes. A importância das fases cristalinas salientando-se a influência do quartzo ajuda a compreender o comportamento mecânico. Do mesmo modo, aspectos da cristalização da mulita são abordados. As microestruturas são mostradas separando-se as análises com e sem fase vítrea, determinado pelo método de preparação das amostras, com intuito de ser mais claro e didático. Esta técnica de análise tem muito a oferecer para o aumento e controle da qualidade de peças de porcelana, sendo que os resultados aqui apresentados podem ser expandidos para todas cerâmicas triaxiais em geral.

\section{Revisão na literatura}

A microestrutura de porcelanas caracteriza-se pela presença de fases cristalinas, onde se podem distinguir os contornos das partículas mais refratárias, envolvidas por uma matriz vítrea que atua como um cimento ligando todas partículas. Não raro, nota-se também a presença de poros e bolhas de gás aprisionadas na fase vítrea. Essa microestrutura vai ser fortemente influenciada pela temperatura de queima, pelo diâmetro de partícula e pela natureza das matérias-primas, como a sua composição química, por exemplo, o teor de óxidos alcalinos em um feldspato. Diversos autores encontraram como principais fases o quartzo, a mulita e a fase vítrea [1-3], sendo estes os principais constituintes de uma porcelana.

A mulita pode ser observada na microestrutura de uma porcelana na forma de escama e de agulhas. Por originar-se do caulim, a mulita na forma de escama é denominada primária. A mulita que cristaliza a partir do feldspato fundido apresenta a forma de agulhas, facilmente identificável, é denominada secundária. A mulita, a partir do caulim puro, só apresenta a forma de agulhas a temperaturas mais altas com o crescimento de grão, enquanto em uma porcelana pode-se encontrá-la em temperaturas mais baixas, auxiliadas pela presença do feldspato fundido $[3,4]$.

O trabalho de Schüller salienta a influência da temperatura de queima e do tamanho de partícula do quartzo sobre a microestrutura [3]. A queima a $1280{ }^{\circ} \mathrm{C}$ resulta em mulita na forma de agulhas na microestrutura, enquanto que a $1400{ }^{\circ} \mathrm{C}$ a maior parte da mulita secundária é dissolvida. Quando se utiliza quartzo de granulometria grosseira, encontra-se presente a mulita secundária, mas ao utilizar quartzo de partículas mais finas, o autor observou novamente que a mulita secundária é dissolvida.

Iqbal e Lee, utilizando microscópio eletrônico de varredura com EDX, demonstraram que a composição química da mulita primária $\left(\mathrm{Al}_{2} \mathrm{O}_{3} / \mathrm{SiO}_{2}=2\right)$ é diferente da mulita secundária $\left(\mathrm{Al}_{2} \mathrm{O}_{3} / \mathrm{SiO}_{2}=1,5\right)[5]$.

Outro aspecto importante característico da microestrutura de porcelanas é a presença de porosidade em volta das partículas de quartzo, devido à relaxação de tensão entre os grãos de quartzo e a fase vítrea. Isto ocorre pela diferença de expansão térmica do cristal de quartzo (coeficiente de expansão linear $23 \times 10^{-6} \mathrm{~K}^{-1}$ ) e do vidro (coeficiente de expansão linear $3 \times 10^{-6} \mathrm{~K}^{-1}$ ) no intervalo de temperatura entre 20 e $750{ }^{\circ} \mathrm{C}$. A trinca em um grão de quartzo está diretamente relacionada com o tamanho do grão. Assim, grãos maiores que $30 \mu \mathrm{m}$ têm a tendência de fraturar [5].

A presença de bolhas na microestrutura explica a diminuição da densidade de peças queimadas a temperaturas mais altas. As bolhas são formadas nas regiões do feldspato que contêm os grupos $\mathrm{OH}^{-}$e nitrogênio, mas ficam retidas nas regiões das partículas remanescentes de argila e não na região do vidro derivado do feldspato. Isto sugere que as bolhas se formam na região de menor viscosidade (feldspato fundido), nos estágios iniciais da sobre queima. Contudo, em temperaturas mais altas, a viscosidade reduzida facilita o escape destes gases que acabam ficando retidos na argila remanescente mais viscosa (região de relictos da argila e "argila fundida") [6].

Kobayashi et al. [7] afirmam que em temperaturas elevadas acontece uma melhor sinterização da peça perto da superfície, restando uma maior concentração de poros no interior da peça, analisando-se a microestrutura em um corte transversal em uma amostra. A formação de uma densa camada próxima à superfície leva a um abrupto aumento da resistência mecânica em temperaturas superiores a $1200{ }^{\circ} \mathrm{C}$, conforme os experimentos de Kobayashi. Este autor apresenta ainda o efeito da temperatura sobre a microestrutura de porcelanas, fazendo ainda uma analogia com a resistência mecânica.

A composição dos feldspatos tem forte influência na microestrutura final, uma vez que ela determina a viscosidade da fase vítrea que, sabidamente, influencia o crescimento das fases cristalinas e até o formato de poro [8, 9]. A precipitação de fases cristalinas libera gases dissolvidos, como oxigênio e nitrogênio, responsável pela formação de uma segunda porosidade [8].

Mörtel et al. [8] salientaram também que as propriedades de porcelanas, como a deformação em queima rápida, são influenciadas por diferenças na taxa de sinterização em diferentes locais em uma mesma peça. Isto é atribuído a diferenças na densidade de empacotamento e conseqüente diferença na condutividade térmica, ressaltando-se a importância da máxima homogeneidade dos corpos cerâmicos. $\mathrm{Na}$ investigação por EDS, Iqbal e Lee [5] mostraram que a composição química da fase vítrea muda para diferentes regiões analisadas, o que também foi referido por Ohyra [10]. Assim tem-se, além do enriquecimento de sílica próximo a partícula de quartzo, o que poderia ser esperado, também a variação do teor de álcalis em diferentes pontos. Portanto, a utilização de fundentes em menor tamanho de partícula, bem como a otimização do processamento, podem ser realizados no sentido de aumentar a homogeneidade macroscópica da fase vítrea durante o processo de queima, o que deve reduzir também a deformação piroplástica. Esta é conseqüência da viscosidade local na fase vítrea (em uma microrregião), sendo menos importante a viscosidade global da mesma [11].

\section{MATERIAIS E MÉTODOS}

As matérias-primas utilizadas nas formulações de massas cerâmicas foram utilizadas na proporção de $50 \%$ de caulim, $25 \%$ de quartzo e $25 \%$ de feldspato, tipicamente de uma 
Tabela I - Composição química das matérias-primas. [Table I - Chemical composition of the raw materials.]

\begin{tabular}{cccc}
\hline$(\%)$ & Caulim & Feldspato & Quartzo \\
\hline $\mathrm{SiO}_{2}$ & 46,96 & 67,02 & 99,81 \\
\hline $\mathrm{Al}_{2} \mathrm{O}_{3}$ & 38,05 & 19,22 & 0,12 \\
\hline $\mathrm{Fe}_{2} \mathrm{O}_{3}$ & 0,46 & 0,19 & 0,08 \\
\hline $\mathrm{MnO}$ & 0,008 & 0,007 & 0,002 \\
\hline $\mathrm{MgO}$ & 0 & 0 & 0,01 \\
\hline $\mathrm{CaO}$ & 0,02 & 0,06 & 0,01 \\
\hline $\mathrm{Na}_{2} \mathrm{O}$ & 0,03 & 3,75 & 0,03 \\
\hline $\mathrm{K}_{2} \mathrm{O}$ & 1,14 & 9,42 & 0,06 \\
\hline $\mathrm{TiO}_{2}$ & 0,03 & 0 & 0,073 \\
\hline $\mathrm{P}_{2} \mathrm{O}_{5}$ & 0,108 & 0,035 & 0,02 \\
\hline $\mathrm{PF}$ & 13,2 & 0,3 & 0,1 \\
\hline $\mathrm{Total}$ & 99,99 & 100 & 99,9 \\
\hline
\end{tabular}

porcelana tradicional. Empregou-se quartzo e caulim comerciais, utilizados pela indústria local e um feldspato potássico. A Tabela I apresenta a análise química das matériasprimas por fluorescência de raios $\mathrm{X}$.

A análise das fases cristalinas foi realizada por difratometria de raios $\mathrm{X}$, revelando a presença de caulinita $\left(\mathrm{Al}_{2} \mathrm{Si}_{2} \mathrm{O}_{5}(\mathrm{OH})_{4}\right)$, como fase principal, muscovita $\left(\left(\mathrm{KAl}_{2}\left(\mathrm{AlSi}_{3} \mathrm{O}_{10}\right)(\mathrm{OH})_{2}\right)\right.$ e ilita $\left(\mathrm{KAl}_{3} \mathrm{Si}_{3} \mathrm{O}_{10}(\mathrm{OH})_{2}\right)$, como fases secundárias.

O caulim é $100 \%$ passante na peneira ABNT $325(0,045 \mathrm{~mm})$. O quartzo é procedente da jazida de Jaguaruna-SC e beneficiado no local. Recebe da empresa a denominação "farinha de sílica" por tratar-se de um quartzo moído, sendo também 100\% passante na peneira ABNT 325.

O feldspato é proveniente do Município de Cristal - RS. A análise por difração de raios $\mathrm{X}$ revelou a presença de duas fases principais: microclínio $\left(\mathrm{KAlSi}_{3} \mathrm{O}_{8}\right)$ e albita $\left(\mathrm{NaAlSi}_{3} \mathrm{O}_{8}\right)$. $\mathrm{O}$ pequeno teor de albita não afeta a translucidez das peças. Este material foi utilizado em granulometria $100 \%$ passante em ABNT 270 (0,053 mm).

As matérias-primas foram moídas a seco em moinho de bolas tipo "periquito"; após, foram umidecidas com água e granuladas, passando por peneira em malha ABNT $20(0,85$ $\mathrm{mm}$ ). A seguir, foram compactadas em prensa hidráulica. Após a prensagem, os corpos-de-prova mediram aproximadamente $8 \times 20 \times 60 \mathrm{~mm}^{3}$.

Os corpos-de-prova foram secos durante $48 \mathrm{~h}$ ao ar livre e ficaram em estufa a $110{ }^{\circ} \mathrm{C}$ por mais $24 \mathrm{~h}$. Foram então sinterizados em forno elétrico tipo mufla. A taxa de aquecimento foi de $150 \mathrm{~K} / \mathrm{h}$ até alcançar a temperatura máxima, onde permaneceram por $30 \mathrm{~min}$. As temperaturas de queima utilizadas foram de $1200{ }^{\circ} \mathrm{C}$ até $1420{ }^{\circ} \mathrm{C}$. Os ensaios de caracterização tecnológica foram conforme os procedimentos do Laboratório de Materiais Cerâmicos - LACER/UFRGS, baseados nas normas ASTM C - 133. O módulo de ruptura foi ensaiado por flexão de quatro pontos.

As amostras preparadas para análise microestrutural foram cortadas dos corpos-de-prova utilizando-se serra circular e lixadas utilizando-se lixas de grana em ordem crescente. $\mathrm{O}$ polimento final foi realizado em politriz com manta de feltro e suspensão de alumina em água. As amostras foram metalizadas com ouro. Dependendo do objetivo da análise, as amostras foram submetidas a ataque ácido com ácido fluorídrico $20 \%$ por $10 \mathrm{~s}$ a $20^{\circ} \mathrm{C}$, para ataque da fase vítrea superficial. A microestrutura foi analisada em microscópio eletrônico de varredura Philips XL 20 com análise química puntual por sistema de energia dispersa em espectroscopia de raios $\mathrm{X}(\mathrm{EDS})$.

\section{RESULTADOS E DISCUSSÃO}

Os dados de caracterização tecnológica das amostras são apresentados na Tabela II, mostrando-se a influência de cada temperatura sobre cada propriedade. A melhor temperatura

Tabela II - Caracterização tecnológica em relação à temperatura de queima. Média de 10 valores.

[Table II - Some parameters for different calcination temperatures.]

\begin{tabular}{ccccccc}
\hline $\begin{array}{c}\text { Temperaturas } \\
\text { de queima }\left({ }^{\circ} \mathrm{C}\right)\end{array}$ & $\begin{array}{c}\text { Perda } \\
\text { de peso. }(\%)\end{array}$ & $\begin{array}{c}\text { Retração } \\
(\%)\end{array}$ & $\begin{array}{c}\text { Abs. de } \\
\text { água }(\%)\end{array}$ & $\begin{array}{c}\text { Poros. } \\
\text { aparente }(\%)\end{array}$ & $\begin{array}{c}\text { Dens. } \\
\left(\mathrm{g} / \mathrm{cm}^{3}\right)\end{array}$ & $\begin{array}{c}\text { MOR } \\
(\mathrm{MPa})\end{array}$ \\
\hline 1200 & 7,4 & 8,2 & $5,50^{0,96}$ & 12,20 & $2,22^{0,03}$ & $24^{2,6}$ \\
\hline 1240 & 7,3 & 10,2 & $2,60^{0,30}$ & 6,00 & $2,35^{0,01}$ & $28^{1,5}$ \\
\hline 1280 & 7,4 & 11,5 & $1,50^{0,20}$ & 3,70 & $2,41^{0,02}$ & $36^{3,5}$ \\
\hline 1320 & 7,4 & 12,2 & $0,46^{0,08}$ & 1,10 & $2,47^{0,01}$ & $38^{3,5}$ \\
\hline 1340 & 7,3 & 12,2 & $0,34^{0,17}$ & 0,84 & $2,48^{0,01}$ & $46^{2,5}$ \\
\hline 1380 & 7,4 & 11,7 & $0,22^{0,09}$ & 0,54 & $2,42^{0,01}$ & $41^{4,7}$ \\
\hline 1420 & 7,6 & 7,25 & $0,59^{* * *, 09}$ & 1,28 & $2,16^{0,02}$ & $25^{3,1}$ \\
\hline
\end{tabular}

obs: os números sobrescritos equivalem ao desvio padrão.

** expansão de gases 
para queima desta formulação foi $1340{ }^{\circ} \mathrm{C}$, na qual as peças apresentaram maior densidade.

\section{Microestrutura}

De um modo geral, a análise da microestrutura revelou a presença de partículas de quartzo e mulita, fase vítrea, poros, trincas e bolhas de gás aprisionadas na fase vítrea. Tanto as partículas de quartzo quanto os poros ou bolhas variaram de tamanho e quantidade, conforme a temperatura de queima.

\section{Microestrutura sem ataque químico}

A microestrutura da porcelana foi investigada para as amostras queimadas e preparadas por lixamento e polimento. Nenhum processamento químico foi utilizado que promovesse alterações da fase vítrea.

$\mathrm{Na}$ microestrutura da amostra queimada a $1200{ }^{\circ} \mathrm{C}$ (Fig. 1), observa-se uma textura ainda irregular. Embora a vitrificação já seja expressiva, possivelmente, não foi suficiente para envolver todas as partículas mais refratárias da amostra. Na Fig. 1 está evidente a presença de porosidade aberta.

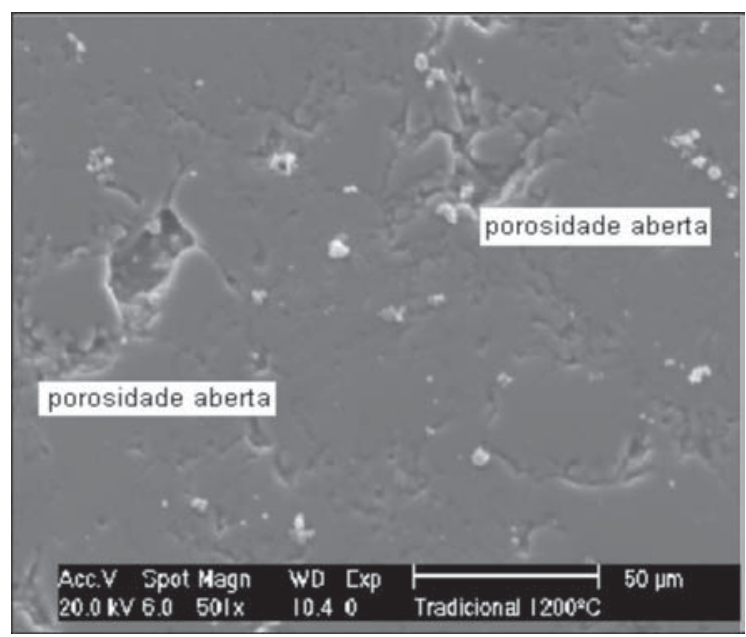

Figura 1: Fotomicrografia em MEV da seção transversal da amostra queimada a $1200^{\circ} \mathrm{C}$.

[Figure 1: SEM photomicrograph of transversal section of the sample fired at $\left.1200{ }^{\circ} \mathrm{C}.\right]$

Na temperatura de $1340{ }^{\circ} \mathrm{C}$ (Fig. 2), constatou-se que a amostra apresenta uma porosidade menor do que as amostras queimadas em temperaturas inferiores, provavelmente pela maior reação entre o líquido formado e a fase cristalina. A superfície da amostra apresenta-se livre de porosidade aberta, explicando os baixos valores de absorção de água e porosidade aparente. Em $1380{ }^{\circ} \mathrm{C}$, a porosidade fechada se mantém praticamente similar à porosidade em $1340^{\circ} \mathrm{C}$. Mas, em $1420^{\circ} \mathrm{C}$, a expansão dos gases (bloating) foi bastante significativa, representada por bolhas aprisionadas na fase vítrea de maior diâmetro. Nesta temperatura a ocorrência de expansão de gases explica a deterioração da qualidade das amostras.
A expansão dos gases nos poros leva a presença de poros maiores do que em temperaturas inferiores aumentando a porosidade fechada, porém a porosidade aberta deve diminuir porque a quantidade de fase vítrea tende a aumentar. $\mathrm{O}$ aumento do valor de absorção de água mostrada na Tabela II deve-se somente a maior superfície da peça, de acordo com o menor valor de retração também mostrado na Tabela II.
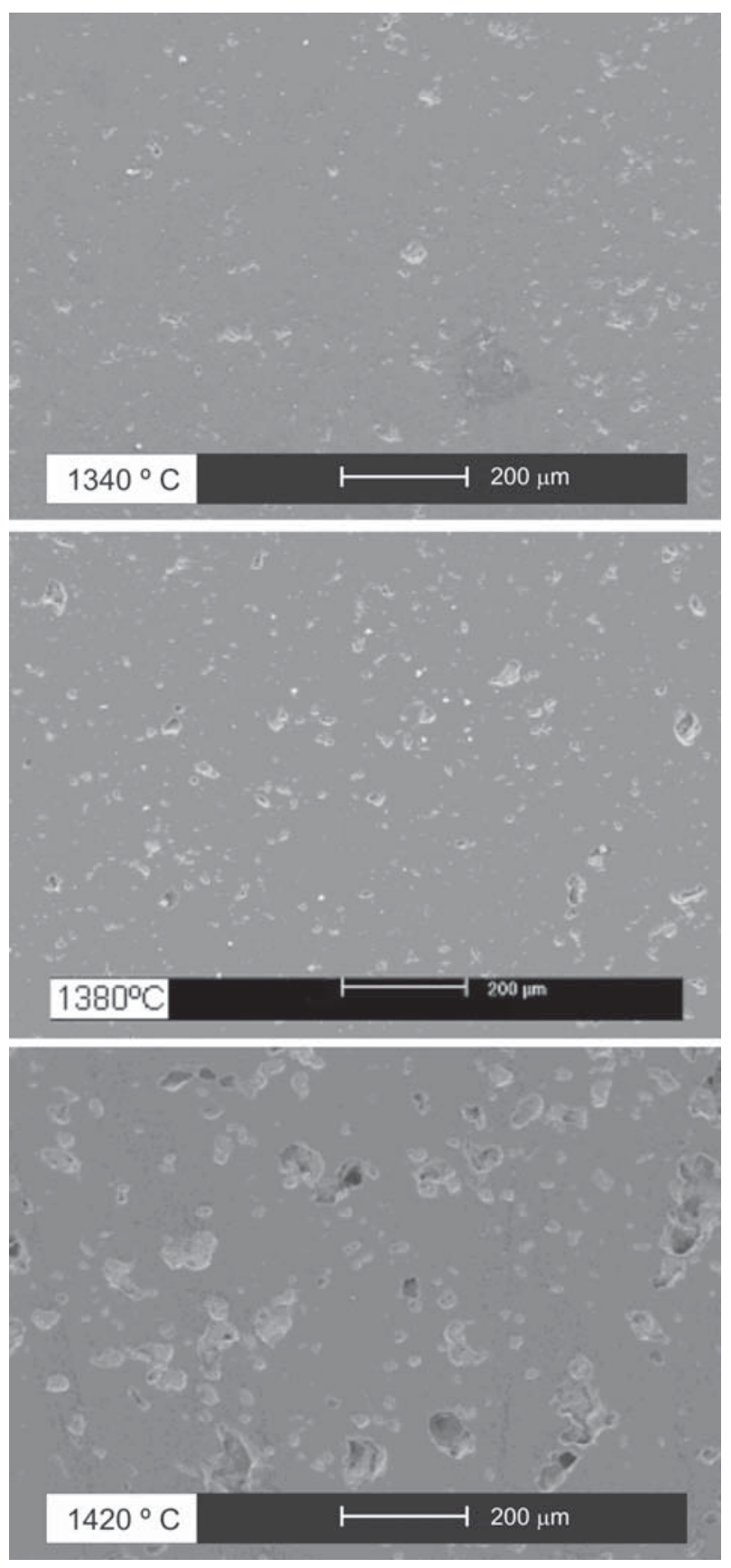

Figura 2: Fotomicrografia em MEV da amostra queimada a $1340{ }^{\circ} \mathrm{C}$, $1380{ }^{\circ} \mathrm{C}$ e $1420{ }^{\circ} \mathrm{C}$.

[Figure 2: SEM photomicrograph of sample surface fired at $1340{ }^{\circ} \mathrm{C}$, $1380^{\circ} \mathrm{C}$ and $1420^{\circ} \mathrm{C}$.] 
Um aumento da absorção de água na queima foi apresentado nos trabalhos de S. Mayti [12], M. F. Abadir [13] e H. Mörtel [8]. Em alguns trabalhos, os autores alegam que o oxigênio molecular $\left(\mathrm{O}_{2}\right)$ liberado da dissociação do $\mathrm{Fe}_{2} \mathrm{O}_{3}$ explicado em Kobayashi [7], pode causar um aumento na absorção de água. Esta explicação carece, no entanto, de maior embasamento, já que isto só faz sentido se houver $\mathrm{Fe}_{2} \mathrm{O}_{3}$ cristalino em quantidade significativa, uma vez que o Fe tende a ficar ligado na estrutura vítrea, formando um eutético com a sílica [14].

A Fig. 3 apresenta em detalhe um grão, em matriz vítrea, com seu contorno bem delineado, o que sugere ser um grão de quartzo. Algumas conclusões advêm desta imagem: i) o quartzo está separado da fase vítrea e ii) o tamanho de grão de aproximadamente $45 \mu \mathrm{m}$ indica que esta granulometria é grosseira para a dissolução/reação entre o quartzo e o líquido, apesar de razoável teor de sódio no feldspato (Tabela I). Podese também observar uma trinca entre os grãos de quartzo (grão maior e grão menor). Os poros indicados, adjacentes ao grão de quartzo, podem ser grãos arrancados devido à preparação da amostra para a microscopia, ou a destruição pelo polimento de alguma porosidade fechada.

Na Fig. 4 pode-se observar uma partícula de quartzo fraturada. Isto prova que a tensão térmica residual foi alta suficiente para quebrar a partícula durante o resfriamento das peças. Este fato é bastante importante no estudo do comportamento mecânico das porcelanas, o que pode explicar a baixa resistência mecânica de peças que utilizam quartzo deste tamanho de partícula. A importância do uso da microscopia no estudo do comportamento mecânico, bem como uma discussão detalhada sobre a importância do quartzo no controle da resistência mecânica foi apresentado em trabalhos recentes $[15,16]$. Como visto o quartzo pode apresentar-se fraturado (Fig. 4) ou não (Fig. 3). Isto é explicado como conseqüência da anisotropia na expansão térmica do quartzo e diferentes propriedades da fase vítrea ao redor dos

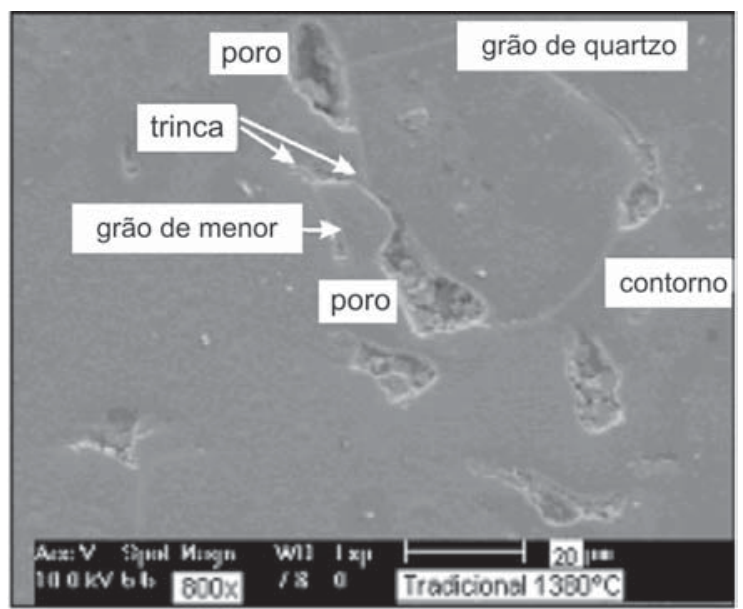

Figura 3: Fotomicrografia em MEV da superfície da amostra queimada a $1380^{\circ} \mathrm{C}$. Trinca periférica ao quartzo.

[Figure 3: SEM photomicrograph of sample surface fired at $1380^{\circ} \mathrm{C}$. Circumferential cracking on quartz grain.]

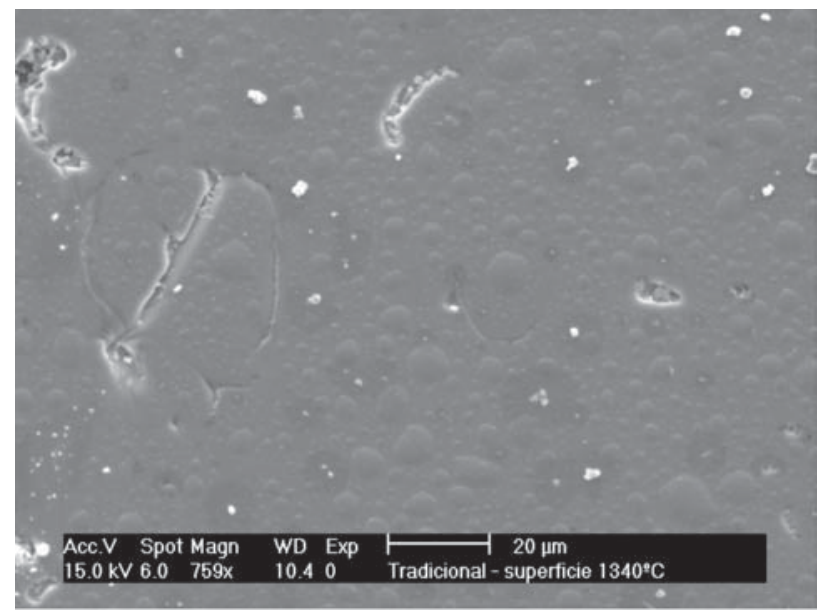

Figura 4: Fotomicrografia em MEV da superfície da amostra queimada a $1340{ }^{\circ} \mathrm{C}$, mostrando fratura no grão de quartzo.

[Figure 4: SEM photomicrograph of the sample fired at $1340{ }^{\circ} \mathrm{C}$. Cracked quartz grain.]

grãos de quartzo (composição química e quantidade de porosidade), existindo diferentes possibilidades de relaxação de tensões.

De acordo com Kingery [17], a temperatura de queima ideal é proporcional às densidades obtidas. Então, a melhor temperatura de queima pode ser relacionada com a qualidade e quantidade da fase vítrea formada (e propriedades desta, como viscosidade e tensão superficial). A fase líquida formada proporciona a retração das peças reduzindo a porosidade, e esta fase líquida deve preencher os poros, trincas e defeitos, sem permitir um aumento significativo do tamanho de bolhas. Ao contrário, a formação de poros perfeitamente arredondados não é deletéria às propriedades [7]. No entanto, durante o resfriamento, após a temperatura de transição vítrea, podem se formar trincas no vidro em conseqüência de tensões térmicas induzidas. Estas trincas podem ser visualizadas na Fig. 5, em amostras preparadas sem polimento, mostrando a superfície, onde este tipo de trinca é mais crítico em relação a resistência mecânica por flexão. A relação entre o tamanho de partícula de quartzo e a formação de trincas e interconexão de trincas foram explicas por Warshaw e Seider [18].

\section{Microestrutura com ataque químico}

Para sua análise, as amostras sofreram ataque por ácido fluorídrico (HF). Assim, parte da fase vítrea reage com o ácido e é dissolvida, restando as fases cristalinas que possuem maior resistência ao ácido. O tempo de reação é controlado para impedir a remoção das fases cristalinas.

A Fig. 6 apresenta a amostra queimada na temperatura de $1240{ }^{\circ} \mathrm{C}$, após ataque químico. A microestrutura revelada por este método apresenta uma matriz vítrea ligando as partículas cristalinas. Constatou-se a presença de quartzo que por apresentar contorno bastante regular, sugere alguma reação deste com a fase líquida, e a presença de outra fase rica em silício e alumínio (como comprova a análise em microssonda 

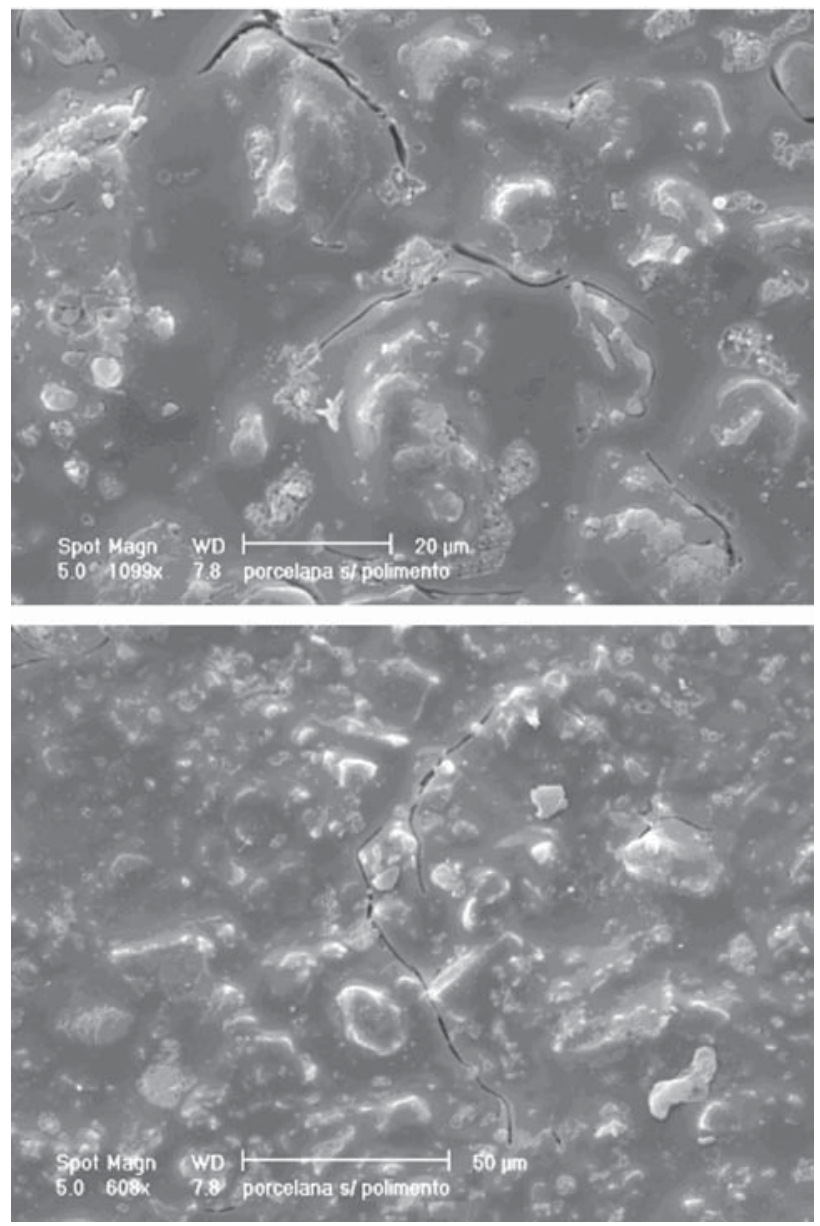

Figura 5: Fotomicrografia em MEV da superfície das amostras preparadas sem polimento. As trincas são decorrência de tensões por diferenças do coeficiente de expansão térmica entre fases.

[Figure 5: SEM photomicrograph of sample surface without polishing. Cracks were formed due to stress generated as a consequence of phases thermal expansion mismatch.]

de raios $\mathrm{X}$, acoplada ao $\mathrm{MEV}$, realizada simultaneamente à análise das imagens), possivelmente uma partícula remanescente de argila (ou aglomerado), onde pode ter cristalizado mulita. Na matriz, encontram-se relictos de feldspato, de contraste mais claro que o quartzo.

A microestrutura da peça queimada a $1340^{\circ} \mathrm{C}$ (Fig. 7) pode ser dividida em três regiões, conforme Iqpal e Lee [5]: região da $\operatorname{argila~(A),~região~do~feldspato~(F)~e~partículas~de~quartzo~}$ (Q). Completa a microestrutura da amostra a fase vítrea superficial, cuja análise foi apresentada no item anterior, não podendo ser observada aqui. Em cada região, a ação do calor ocasionará mudanças das fases pertinentes, de acordo com a composição química e mineralógica específica. O quartzo apresenta variação somente no contorno de grão e como a fase vítrea foi removida, nota-se somente um trincamento percorrendo as partículas de quartzo. Conforme mencionado anteriormente, este trincamento surge no alívio das tensões devido à diferença da contração volumétrica que o quartzo sofre no resfriamento, em relação à matriz. Na região da argila,

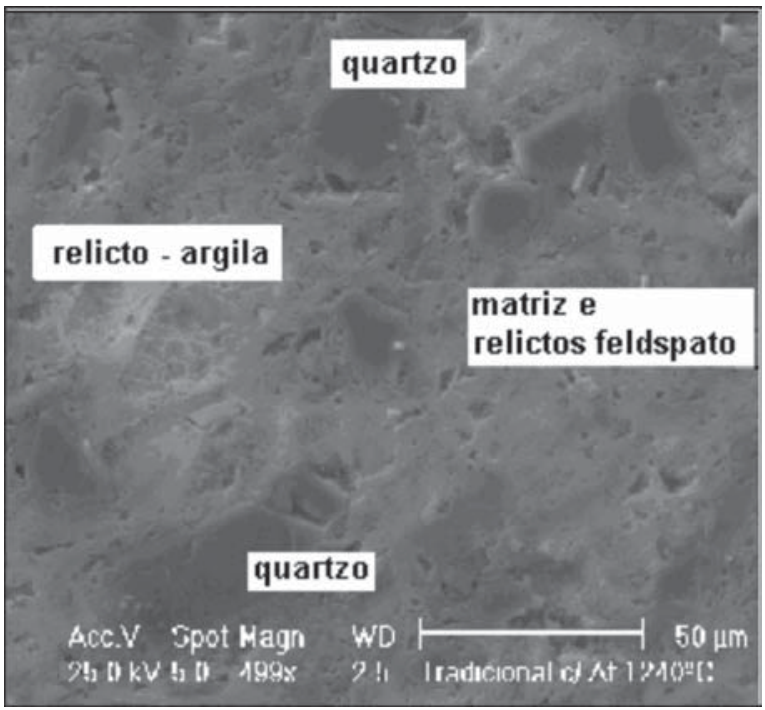

Figura 6: Fotomicrografia em MEV da superfície da amostra queimada a $1240{ }^{\circ} \mathrm{C}$ e atacada com ácido (HF $20 \%$ por $10 \mathrm{~s}$ ).

[Figure 6: SEM photomicrograph of sample surface fired at $1240{ }^{\circ} \mathrm{C}$ and etched with hydrofluoric acid $20 \%$ for 10 s.]

espera-se a formação da mulita primária e na região do feldspato, a mulita secundária. Essa diferenciação é mais bem visualizada na Fig. 8.

A mulita primária e secundária foi encontrada por diversos autores [5, 6, 19, 20]. Iqpal e Lee [5] descrevem a mulita primária como em forma de um agregado de cristais de pequenas dimensões $(<0,5 \mu \mathrm{m})$ formada na região da argila, e a mulita secundária, como em forma característica de uma agulha prismática $(>1 \mu \mathrm{m})$ formada na região do feldspato. Este mesmo autor afirma que a mulita secundária se origina a

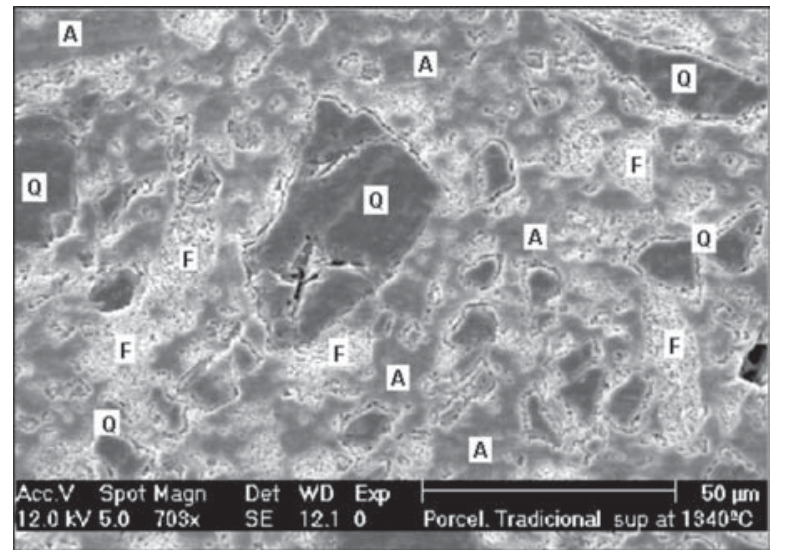

Figura 7: Fotomicrografia em MEV da superfície da amostra queimada a $1340{ }^{\circ} \mathrm{C}$ e atacada com ácido (HF $20 \%$ por $10 \mathrm{~s}$ ). $\mathrm{Q}=$ quartzo; $\mathrm{A}=$ relicto de argila e $\mathrm{F}=$ relicto de feldspato. 700x. [Figure 7: SEM photomicrograph of sample surface fired at $1340{ }^{\circ} \mathrm{C}$ and etched with hydrofluoric acid $20 \%$ for 10 s. $Q=$ quartz; $A=$ clay relict and $F=$ feldspar relict. $700 x$.] 


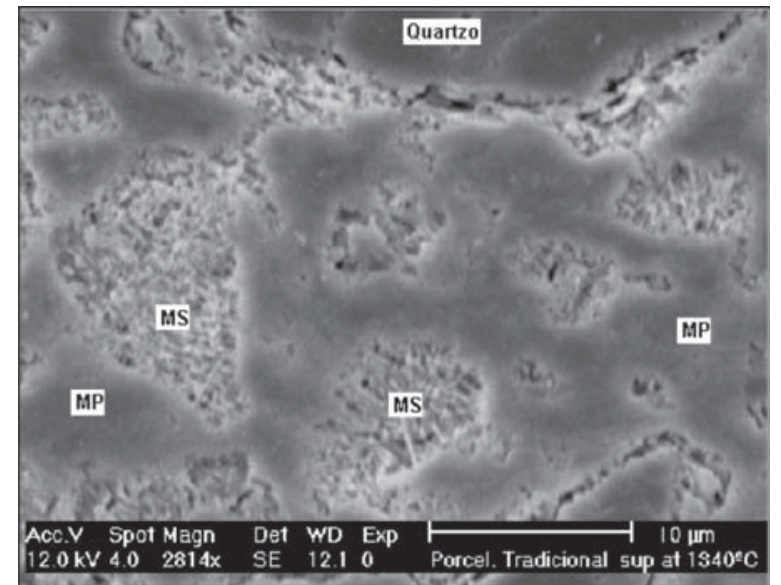

Figura 8: Fotomicrografia em MEV da superfície da amostra queimada a $1340^{\circ} \mathrm{C}$ e atacada com ácido (HF $20 \%$ por 10 s). $\mathrm{MP}=$ mulita primária e MS = mulita secundária. 2800x.

[Figure 8: SEM photomicrograph of sample surface fired at $1340^{\circ} \mathrm{C}$ and etched with hydrofluoric acid $20 \%$ for $10 \mathrm{~s} . \mathrm{MP}=$ primary mullite and $M S$ = secondary mullite. 2800x.]

partir da superfície externa da mulita primária e cresce na região de menor viscosidade (relicto do feldspato). Do mesmo modo, Lundin (em [5]) afirma que a mulita primária serve como semente para a nucleação da mulita secundária.

A Tabela III mostra a análise química puntual por EDX que confirmou as fases presentes, conforme previsto pela análise do aspecto morfológico. Do mesmo modo, a análise por difratometria de raios $\mathrm{X}$ mostrou a presença de quartzo e mulita.

Pela Fig. 9, pode-se observar uma maior concentração de mulita secundária na região próxima à mulita primária. Entretanto, este mesmo aspecto é notado na interface com um grão de quartzo.

Na Fig. 10, utilizou-se uma magnitude ainda maior, ou seja, permite-se o detalhamento de estruturas $<1 \mu \mathrm{m}$. Como esta amostra foi atacada por ácido, salienta-se que toda a amostra está na verdade envolvida pela fase vítrea. Não há necessariamente um contato direto entre as partículas de mulita secundária e primária, sendo, portanto, questionável a hipótese da primária servir de semente para a secundária. As partículas de mulita primária possuem direção aleatória em relação à

Tabela III - Relação entre a análise química por EDX e as fases formadas, conforme a Fig. 7.

[Tabela III - EDS analysis and formed phases, see Fig. 7]

\begin{tabular}{ccc}
\hline $\begin{array}{c}\text { Região } \\
\text { (fase principal) }\end{array}$ & Elementos & Fase Secundária \\
\hline Mulita secundária & $\mathrm{Si}, \mathrm{Al}, \mathrm{O}, \mathrm{K}, \mathrm{Na}$ & $\begin{array}{c}\text { fase vítrea, } \\
\text { relictos feldspato }\end{array}$ \\
\hline Mulita primária & $\mathrm{Si}, \mathrm{Al}, \mathrm{O}$ & relictos argila \\
\hline Quartzo & $\mathrm{Si}, \mathrm{O}$ & \\
\hline
\end{tabular}

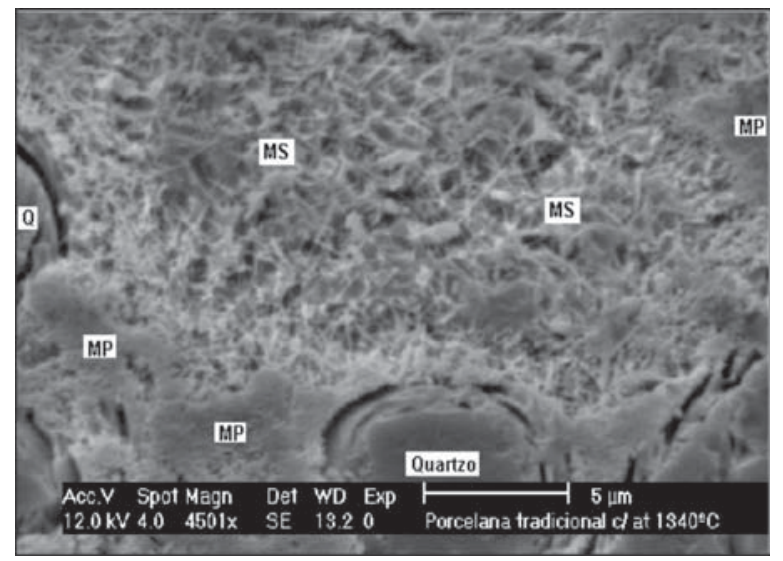

Figura 9: Fotomicrografia em MEV da superfície da amostra queimada a $1340{ }^{\circ} \mathrm{C}$ e atacada com ácido (HF $20 \%$ por $10 \mathrm{~s}$ ). MP = mulita primária e MS = mulita secundária. 4500x.

[Figure 9: SEM photomicrograph of sample surface fired at $1340^{\circ} \mathrm{C}$ and etched with hydrofluoric acid $20 \%$ for 10 s. $M P=$ primary mullite and $M S=$ secondary mullite. $4500 x$.]

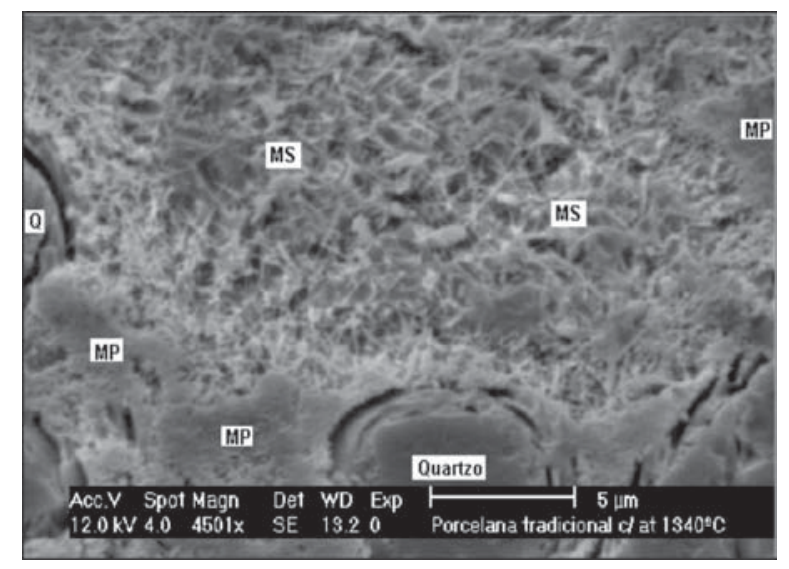

Figura 10: Fotomicrografia em MEV da superfície da amostra queimada a $1340{ }^{\circ} \mathrm{C}$ e atacada com ácido. (HF $20 \%$ por 10 s). 9000x.

[Figure 10: SEM photomicrograph of sample surface fired at $1340^{\circ} \mathrm{C}$ and etched with hydrofluoric acid $20 \%$ for 10s. 9000x.]

mulita primária. Pode-se notar na Fig. 10 pequenas partículas por baixo das agulhas, sendo possivelmente relictos de feldspato. Então, baseado na análise desta imagem, a mulita secundária se forma nos relictos de feldspato, cristalizando-se na matriz vítrea. Esta, por ser líquida, permite elevada difusão, dependendo da temperatura e viscosidade. Assim, mesmo regiões mais afastadas da mulita primária podem adquirir a composição química e conseqüente potencial químico necessário para o crescimento das agulhas, não crescendo necessariamente a partir da mulita primária, embora as hipóteses não sejam excludentes. Assim, esta observação confirma que a cristalização da mulita pode ser explicada pela passagem da fase vítrea para região da mulita, de acordo com o diagrama ternário leucita-mulita-sílica, hipótese já apresentada na literatura [9]. A Fig. 11 mostra a cristalização da mulita secundária somente a partir da transformação da 
mulita primária, sem cristalização na fase vítrea, em uma formulação de fundente de silicatos e sem alumínio, substituindo o feldspato, cujos resultados foram analisados mais detalhadamente em outro artigo [21].

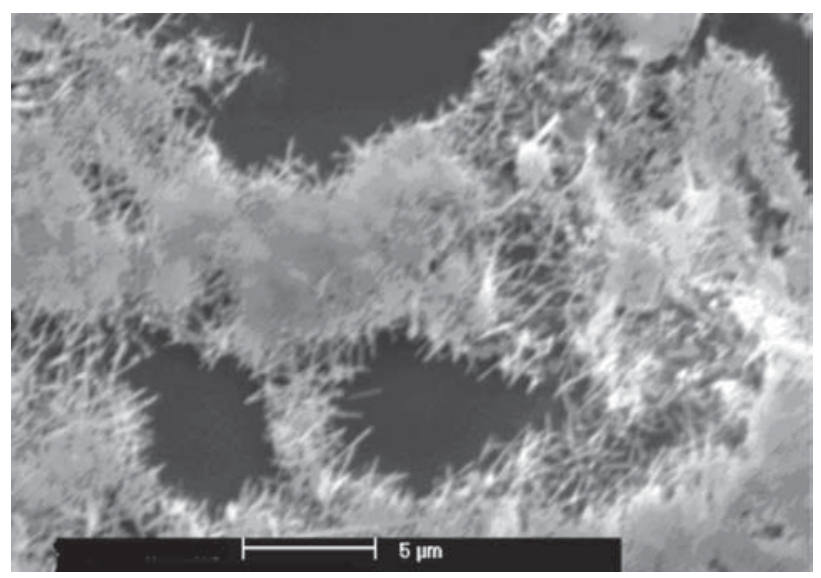

Figure 11: Fotomicrografia em MEV de uma amostra cuja formulação utilizava fundente de silicatos e sem alumínio (substituindo o feldspato), mostrando que a cristalização da mulita secundária dáse somente a partir da mulita primária. Superfície sem polimento e com ataque ácido (HF $20 \%$ por 5 s).

[Figure 11: SEM photomicrograph of glass porcelain unpolished surface. In the batch it was used a flux of silicates without aluminium replacing feldspar. Here secondary mullite was formed only from primary mullite. (Etched, HF $20 \%$ for 5 s).]

A Fig. 12 apresenta a amostra queimada na temperatura de $1420^{\circ} \mathrm{C}$. Observa-se nesta figura grande quantidade de poros. Têm-se poros pequenos e arredondados e poros grandes, podendo se conectar em amplitudes superiores a $200 \mu \mathrm{m}$, o que explica o baixo módulo de ruptura encontrado para estas amostras (Tabela II), referido anteriormente e explicado pela ocorrência de expansão de gases.

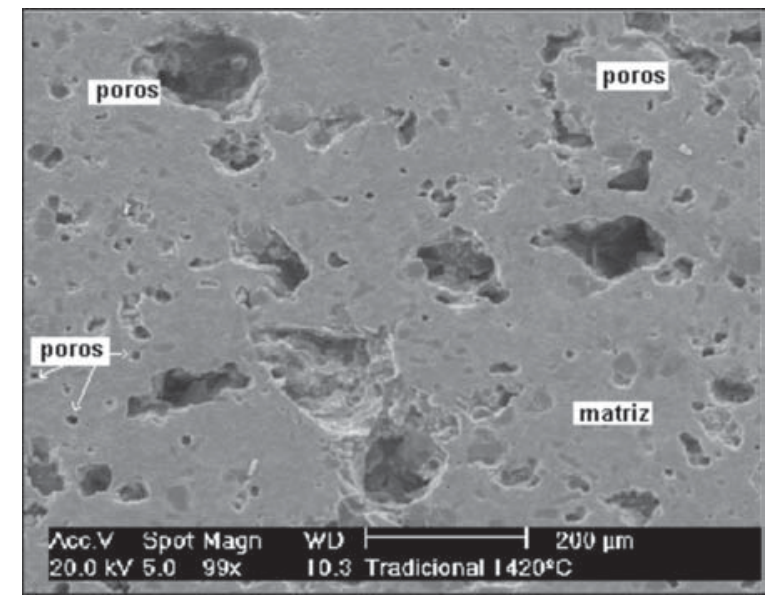

Figura 12: Fotomicrografia em MEV da seção transversal da amostra queimada a $1420^{\circ} \mathrm{C}$ e atacada com ácido fluorídrico a $40 \%$ por 10 s. $9000 x$. [Figure 12: SEM photomicrograph of transversal section of the sample fired at $1420^{\circ} \mathrm{C}$ and etched with hydrofluoric acid $20 \%$ for 10 s.]

\section{CONCLUSÕES}

Pelo estudo da microestrutura, pode-se verificar que a temperatura de sinterização, na qual se alcança menor porosidade e maior módulo de ruptura máximo, é aquela em que foi gerada quantidade suficiente de fase vítrea para cobrir toda a peça, envolvendo as fases cristalinas como o quartzo e a mulita.

Acima da temperatura de resistência máxima, ocorre o aumento da porosidade, através da liberação de gases em consequiência da precipitação e dissolução de fases cristalinas, mas principalmente pela expansão do gás nos poros (porosidade fechada). $\mathrm{O}$ aumento de porosidade e, mais especificamente, o diâmetro dos poros, mostraram-se deletérios à resistência mecânica das peças, como era de se esperar.

Uma partícula de quartzo pode apresentar-se fraturada ou não em decorrência da tensão residual de origem térmica gerada na mesma. Esta tensão sofre forte influência da anisotropia do quartzo e das diferentes propriedades da fase vítrea circundante, o que explicaria a possibilidade de trincamento.

Partículas de quartzo formam trinca periférica ao grão devido a maior contração delas em relação à fase vítrea no resfriamento. De modo semelhante, a diferença do coeficiente de expansão térmica entre as fases causam trincas no vidro formado no resfriamento.

A presença de trincas periféricas às partículas de quartzo e principalmente trincas na fase vítrea (possivelmente interconectadas) e a fratura de grãos de quartzo limitam a resistência mecânica das porcelanas.

A formação de mulita primária é uma consequiência direta da decomposição do caulim com o aumento de temperatura. A formação de mulita secundária dá-se na fase vítrea formada pela fusão do feldspato, sendo fortemente influenciada pela viscosidade e composição química da fase vítrea.

\section{REFERÊNCIAS}

[1] L. Mattyasovszky-Zsolnay, J. Mater. Sci. 40, 9 (1957) 299306.

[2] M. W. Carty, U. Senapati, J. Am. Ceram. Soc. 81, 1 (1998) 3-20.

[3] K. H. Schüller, Trans. Brit. Ceram. Soc. 63, 2 (1967) 103116.

[4] C. Y. Chen, Ceram. Int. 26 (2000) 715-720.

[5] Y. Iqbal, W. E. J. Lee, J. Am. Ceram. Soc. 82, 12 (1999) 3584-90.

[6] Y. Iqbal, W. E. J. Lee, J. Am. Ceram. Soc. 83, 12 (2000) 3121-27.

[7] Y. Kobayashi, O. Ohira, E. Kato, J. Am. Ceram. Soc. 75, 7 (1992) 1801-1806.

[8] H. Mörtel, St. Krebs, K. Pham-Gia, Ber. Dtsch. Keram. Ges. 77, 5 (2000) 26-35.

[9] C. R. Becker, S. T. Misture, W. M. Carty, Ceram. Eng. Sci. Proc. 21, 2 (2000)15-29.

[10] Y. Ohya, Y. Takahashi, J. Am. Cer. Soc. 82, 2 (1999), 445-448.

[11] W. M. Carty, Ceram. Eng. Sci. Proc. 23, 2 (2002) 79-94. 
[12] S. Mayti, B. K. Sarkar, J. Eur. Ceram. Soc. 16 (1996) 1083-1088.

[13] M. F. Abadir, E. H. Sallam, I. M. Bakir, Ceram. Int. 28 (2002) 303-310.

[14] L. van Vlack, "Propriedades dos materiais cerâmicos", Ed. Edgar Blücher, S. Paulo (1973).

[15] S. R. Bragança, C. P. Bergmann, Ceram. Int. 29 (2003) 801-806

[16] S. R. Bragança, C. P. Bergmann, Cerâmica 50, 314 (2004) 145-155.
[17] W. D. Kingery, H. K. Bowen, D. R. Uhlmann, Introduction to ceramics, Wiley (1962).

[18] S. I. Warshaw, R. J. Seider, J. Am. Ceram. Soc. 50, 7 (1967) 337-342.

[19] K. H. Schüller, Ceramics Monographs - A Handbook of Ceramics, Verlag Schmidt GmbH Freiburg Brg. (1979).

[20] C. Prasad, K. N. Maiti, R. Venugopal, Ceram. Int. 28 (2002) 9-15.

[21] S. R. Bragança, C. P. Bergmann, J. Eur. Ceram. Soc. 24 (2004) 2383-2388.

(Rec. 29/07/03, Rev. 26/06/04, Ac. 10/09/04). 